\title{
Manifestation of Tolerance in the Aspect of the Communicative-Pragmatic Approach
}

\author{
Jinling Zhu* \\ Philological Faculty, People s Friendship University of Russia, Moscow, Russia \\ ${ }^{*}$ Corresponding author. Email: zhujl@yandex.ru
}

\begin{abstract}
In the process of communication, linguistic aggressiveness can lead to various contradictions, failure of communication, but linguistic tolerance is one of the most effective means to avoid aggression, guarantee the continuation of communication, and overcome transcultural barriers. The main content of the study is to analyse the problems and the impacts of verbal aggression on communication, to show the role and approaches of tolerance in the regulation of linguistic means and situations. The work has an multi-disciplinary character, is written at the intersection of sociolinguistics, cultural linguistics and psycholinguistics, and is devoted to the current topic of the importance of tolerance in solving practical communicative contradictions in the aspect of communicative-pragmatic approach.
\end{abstract}

Keywords: Tolerance, aggression, Aggressiveness, Communication, Cultural linguistics, Linguistic barrier, Linguistic situation.

\section{INTRODUCTION}

In human life and social development, communication occupies a large share and plays an important role. It becomes the most popular social action in everyday life. People need to rely on communication to make the exchange of information and achieve their specific goals. Communication represents not only the human personality, but also the underlying sociality and its cultural background. It is carried out everywhere and always, especially in relation to the expression of desires or requests in communication. For example, communication takes place in the family, at school, at work, at a wedding, when making official documents, and others. In the process of forming communication, various factors affect the effectiveness and results of communication, including expressive means and communicative principles. This article discusses communicative tolerance in the aspect of the communicative-pragmatic approach and its manifestation in culture.

\section{INFLUENCE OF SOCIAL, CULTURAL AND PERSONAL FACTORS ON COMMUNICATION}

As social development organization of speech involves linguistic level, the human personality, cultural differences, social psychology, communication context, and others, so language learning is not only focused on the study of his system of linguistic personality, but also on the problems associated with interaction between the addresser and the addressee in the practice of communication in order to better understand the real purpose and the basis for the use of appropriate expressive methods.

In communication, the activity of people has a joint specificity as a cooperation of motives, goals, plans and strategies, also depends on the ways of thinking, the positions of both parties, the limitations of personal education levels, religious and cultural differences in the community, so the study of communicative methods also needs to focus on the functions of speech.

The scientist Sidorov considers speech activity as "one of the types of activity that is an impelled need for universal sign coordination, correlated with reality (linguistic and non-linguistic), expedient, internal or 
internal and external activity of the individual, performed in the form of speech-psychological actions and operations using the sign resources of the language system based on the communicative ability and experience of its implementation" [9].

"The communicative aspect of linguistic, focused on the study of the final result - the effect of linguistic communication - can be called the pragmatics of language as its integral characteristic in terms of the mutual influence of interlocutors in the process of communication" [8]. The communicative-pragmatic approach involves taking into account the significant component of language units, which is associated with a person who uses language as a tool of communication and makes his choice to achieve the tasks set when orienting in the situation as a whole, in the social characteristics of the addressee, and so on [13].

In "Stylistic encyclopedic dictionary of Russian language" communication is defined as "the expression in the text by means of linguistic interaction to communicate, understood as the ratio of semantic roles as given the reactions of the recipient (including the second I), as well as explication in the text of the signs actually dialogue" [7].

\section{CORRELATION OF LINGUISTIC AGGRESSIVENESS AND TOLERANCE}

We consider how tolerance manifests itself in expressions from two points of view: verbal aggression and linguistic tolerance.

Cultural mistakes, as a rule, are not forgiven so easily and make the most negative impression. Overcoming the cultural barrier is impossible without a tolerant perception of reality, which is manifested in the loyal and friendly attitude of at least one of the communicants to another. Tolerant perception in negotiations is manifested in linguistic tolerance, which is an essential component of linguistic competence.

It is linguistic competence that helps to achieve optimal results, since very often during dialogues there are conflict situations caused by the fact that "the parties defend their positions in every possible way, trying to force the opponent to make concessions. At the same time, they often resort to false or one-sided arguments, not listening to each other. " [11]. According to Shcherbinina "Such situations are a prerequisite for the emergence of discontent, conflict and, as a consequence, verbal aggression, which, in turn, hinders the implementation of the main tasks of effective speech interaction: it has a destructive effect on the consciousness of participants in communication, makes it difficult to fully exchange information, significantly reduces the possibility of mutual understanding of communicants, blocks the development of a common strategy of interaction" [16].
As Barod and Richardson defined aggression, that any form of behavior aimed at insulting or harming another living being who does not want such treatment" [3].

Vakhrushev noted that "There are different strategies for overcoming linguistic aggression: reflection, empathy and tolerance. And it is tolerance, or rather, its linguistic refraction, that is the most successful and effective strategy for overcoming verbal aggression" [4].

Currently, as noted, aggression is beginning to be intensively studied. A comprehensive study in this area is considered to be the work of Shcherbinina "Verbal aggression". It is significant that the phenomenon of verbal aggression is also studied within the framework of a popular and dynamically developing area of linguistic expertise, highlighted, in particular, in the works of members of the Guild of Linguists-experts (GLADYS) [15].

Chernysheva wrote in her article that verbal aggression as "exceeding the limits of coarsening and vulgarization of the literary linguistic, manifested in the oversaturation of the text with profanity (expletive, with the installation of a rude insult), a negative assessment of the individual through the use of labels, excessive expansion of foreign words and violation of language norms, situationally and stylistically unjustified" [14].

Apresjan in the article "Implicit aggression in language," expressed his aspect: "Under " linguistic aggression" we mean all types of negative or critical attitude of the speaker to the addressee, expressed by using linguistic resources" [1].

Buss defines noted that "Verbal aggression is the expression of negative feelings as through the form (quarrel, cry, squeal), and through the content of verbal responses (threats, cursing, swearing)" [18].

In terms of a working definition, we would support the definition given by Shcherbinina: "verbal (verbal, verbal) aggression is the verbal expression of negative feelings, emotions, intentions in an unacceptable form in a given speech situation" [17].

Despite the listed definitions of verbal aggression, it is difficult to identify whether a particular expression is aggressive. In order to better identify it, we need to consider a specific linguistic situation, communication conditions and necessarily context, in other words, we take into account the relationship with other linguistic units, with their stylistic colouring. Dridze believes that the text cannot be considered as a set of mechanically related elements, because it is "a system of elements of varying degrees of complexity and complexity, functionally united in the structure of a common concept; text combinatorics qualitatively changes the 
information load that each of its elements would carry by itself (outside of the given text)" [5].

According to Bally, any utterance contains two blocks of components-dictum and modus. Dictum is a subject - logical statement, it relates to the description of a certain situation, and modus is the speaker's attitude to these situations, and also expresses the speaker's intellectual, emotional or volitional judgment in relation to the dictum, the so-called subjective modality [2].

\section{THE MANIFESTATION OF TOLERANCE AND ITS COORDINATIONAL EFFECT IN COMMUNICATION}

How to practice modus so that the dictum is moderate? Language tolerance plays an important role in communication.

Tolerance does not imply condescension, but benevolence, readiness for respectful dialogue and cooperation [1].

The famous lexicographer Ushakov in his dictionary defines "tolerance is the ability and skill to tolerate something foreign, to put up with someone else's opinion or character" [12].

In the life of an individual, tolerance is a manifestation of readiness to listen to the opinion of opponents, the ability not to be irritated and not to feel a sense of resentment, humiliation or, conversely, superiority in the process of interaction.

Regarding the manifestation of tolerance in communication, Sternin notes that " the Russian communicative consciousness is looking for an ideal in a tolerant interlocutor, in one who would perform the role of an attentive, polite listener "[10]. As for the national and cultural specifics of communication, Ermakova writes that "tolerance is a distinctive feature of the mentality of any nation" [6]. Tolerance is an integral part of cultural communication.

To avoid aggression in communication, raising the moral atmosphere and considering the speech situation are the main tasks. A healing influence is exerted on the destructive processes of the relationship between the addressee and the addressee by promoting the use of such components of the culture of peace as tolerance, respect, tolerance, and peacefulness.

In addition, tolerance embodies both linguistic behavior and polite forms of linguistic expression in the aspect linguistic culturology.

Due to differences in regions, cultures, religions, etc., different understandings or ambiguities can easily occur in the treatment of the same behavior or the same expression, and even conflicts. The so-called behavior actually refers to the information released by body behavior, that is, body language. If you don't fully understand the other party's culture and customs, it is easy to misunderstand. For example, in the Chinese dining table culture, if a person is pouring wine or tea while the speaker is talking to guests, and it is not convenient for him to stop the conversation, then he usually pinches the thumb, index finger, and middle finger of his right hand together, with the fingertip pointing down, and tap the desktop a few times. It means to thank that person. This is called " Knock refers to the ritual ", and this method is suitable for Chinese banquets. If there are foreigners among the guests, such as russian, then the russian will feel very uncomfortable. Because finger fingering during a meal is very rude and offensive in the Russian dining table culture. Therefore, when the people with different cultural backgrounds communicate together, they often learn about the traditional customs and behaviors of all parties in advance to avoid unnecessary misunderstandings and difficulties in communication.

The linguistic tolerance is not only reflected in the speech etiquette, but also in the linguistic style chosen by the speaker. Linguistic style is a system of linguistic elements united by a certain purpose, methods of their selection, use, mutual combination and correlation. When using linguistic units in a particular sphere or form of speech communication, the so-called stylistic coloring is manifested. Usually such a proper stylistic coloring is accompanied by expressiveness, emotionality, evaluation. Expressive coloring indicates the nature and degree of expression of qualitative or quantitative features of an object, person, action, state, etc. An evaluation moment can be added to the expression: positive or negative.

Usually, one neutral expression has several expressive synonyms that differ in the degree of emotional tension. Bright expression highlights solemn, humorous, and ironic expressions. Different forms and levels of linguistic styles are manifested in choosing appropriate vocabulary, phrases, and sentences, then using appropriate grammar to organize them to achieve the effect of desired information. It can be seen that the linguistic style chosen for speaking can not only reflect the attitude of speaker to the recipient, but also reflect the various communication methods that the speaker can use in order to achieve the purpose of communication.

When studying tolerance and the action of its forms in pragmatic communication, we should pay a attention to the ways and means of their expression, in particular, to the communicative intention of the addressee and the situation of communication, in order to solve the problems of overcoming linguistic barriers. Understanding the addressee and the addressee's behavioral tactics is also helped by nonverbal means of communication and remarks that promote communication, including tolerant communication. In 
cross-cultural communication, it is extremely important to follow the norms of tolerance, which imply mutual respect for the cultural characteristics of each other by the participants of the speech act.

\section{CONCLUSION}

The study of linguistic aggressiveness and tolerance is a topical topic. Mastering linguistic tolerance helps to solve the problem of verbal aggression in communication, reduce the level of discourse, reduce the negative impact of discourse, express a tolerant attitude to the object and ultimately achieve a communicative intention. The study of linguistic tolerance and verbal aggressiveness complements the existing and developed principles and standards of intercultural communication. It has practical and theoretical significance in cross-cultural communication education, training of professional talents and in-depth research of the pragmatic direction from aspect language culturology.

\section{REFERENCES}

[1] V.Yu. Apresyan, Implicit aggression in language/ / Computer linguistics and intellectual technologies: Tr. Intern. Conf. "Dialog 2003", Moscow: Nauka, 2003, pp. 32-35.

[2] H. Bally, General linguistics and questions of the French language / Sh. Bally. - Moscow: Izd-vo inostr. lit-ry, 1955 , p. -416 .

[3] R. Baron, D. Richardson, Aggression. St. Petersburg: Piter, 1998. p.-336.

[4] A.A. Vakhrushev, Verbal aggression and language tolerance in intercultural business communication / Bulletin of the chelyabinsk state university. 2010. No. 4. pp. 53-58.

[5] T.M. Dridze, Interpretational characteristics and interpretation of texts (taking into account the specifics of interpretational shifts) / / Semantic perception of a speech message (in the conditions of mass communication). Moscow, 1976.
[6] O.P. Ermakova, Tolerance and some features of the Russian mentality in the mirror of language: Moscow: OLMA-PRES, 2005

[7] M.N. Kozhina, Stylistic encyclopedic dictionary of the Russian language /M. N. Kozhina. - M.: Flint, 2003, p. -696.

[8] G.V. Kolshansky, Pragmatika yazyka / Kolshansky G. V. // Linguistics and methodology in higher school: sb. nauch. tr. / Kolshansky G. V.. - M.: Prosveshchenie, 1980. pp. 3-8.

[9] E.V. Sidorov, General theory of speech communication: Textbook. - M.: Publishing House of the Russian State University, 2010.

[10] I.A. Sternin, Tolerance and communication // Philosophical problems of tolerance - M.: OLMAPRESS, 2005.

[11] Unt, I. The art of negotiating 12. rov. M.: Balance Club, 2004. p. -152 .

[12] D.N. Ushakov, Explanatory dictionary of the modern Russian language/Ed.d-RA filol. Tatyanchenko N. F. - M., 2005

[13] N.I. Formanovskaya, Speech communication: a communicative and pragmatic approach / N. I. Formanovskaya, Moscow: Russian Language, 2002, p.-216.

[14] T.V. Chernysheva, Stylistic analysis as the basis of linguistic expertise of a conflict text. The Russian language in its natural and legal existence. Barnaul, 2000, pp. 206-213.

[15] Yu.V. Shcherbinina, Verbal aggression. - ed. 2-E.M.: LKI Publishing House, 2008

[16] Yu.V. Shcherbinina, Russian language: Speech aggression and ways to overcome it: Textbook. Moscow: Flint : Nauka, 2004.

[17] Yu.V Shcherbinina, Verbal aggression. - M.: Komkniga, 2006, p.-360.

[18] A.H. Buss, Aggression pays // The Control of Aggression and Violence. NY, London, 1971 